Article

\title{
Divergent Effects of Resveratrol on Rat Cardiac Fibroblasts and Cardiomyocytes
}

\author{
Xavier Lieben Louis ${ }^{1,2}$, Zach Meikle 1,2, Laura Chan 1,2, Garret DeGagne ${ }^{1,2}$, \\ Rebecca Cummer ${ }^{1}$, Shannon Meikle ${ }^{1}$, Sampath Krishnan ${ }^{1,3}$, Liping Yu ${ }^{3,4}$, \\ Thomas Netticadan ${ }^{3,4,5, *}$ and Jeffrey T. Wigle ${ }^{1,2, *(D)}$ \\ 1 Institute of Cardiovascular Sciences, St. Boniface Hospital Albrechtsen Research Centre, Winnipeg, \\ MB R2H 2A6, Canada \\ 2 Department of Biochemistry and Medical Genetics, University of Manitoba, Winnipeg, MB R3E 0J9, Canada \\ 3 Canadian Centre for Agri-Food Research in Health and Medicine, St. Boniface Hospital Albrechtsen \\ Research Centre, Winnipeg, MB R2H 2A6, Canada \\ 4 Agriculture and Agri-Food Canada, Winnipeg Winnipeg, MB R2H 2A6, Canada \\ 5 Department of Physiology and Pathophysiology, University of Manitoba, Winnipeg, MB R3E 0J9, Canada \\ * Correspondence: tnetticadan@sbrc.ca (T.N.); jwigle@sbrc.ca (J.T.W.); Tel.: +204-237-2691 (T.N.); \\ +204-235-3953 (J.T.W.)
}

Academic Editor: Philippe Jeandet

Received: 11 April 2019; Accepted: 12 July 2019; Published: 17 July 2019

\begin{abstract}
In this study, we tested the potential cardioprotective effects of the phytoalexin resveratrol (Rsv) on primary adult rat cardiac fibroblasts (CF), myofibroblasts (MF) and cardiomyocytes. Adult rat $\mathrm{CF}$ and cardiomyocytes were isolated from male 10-week old Sprague-Dawley rats, cultured for either $24 \mathrm{~h}$ (cardiomyocytes) or $48 \mathrm{~h}$ (CF) before treatments. To isolate MF, CF were trypsinized after $48 \mathrm{~h}$ in culture, seeded in fresh plates and cultured for $24 \mathrm{~h}$ prior to treatment. All three cells were then treated for a further $24 \mathrm{~h}$ with a range of Rsv doses. In CF and MF, cell proliferation, viability, apoptosis assays were performed with or without Rsv treatment for $24 \mathrm{~h}$. In cardiomyocytes, cell viability and apoptosis assay were performed $24 \mathrm{~h}$ after treatment. In separate experiments, CF was pre-incubated with estrogen, tamoxifen and fulvestrant for $30 \mathrm{~min}$ prior to Rsv treatment. Rsv treatment decreased proliferation of both fibroblasts and myofibroblasts. Rsv treatment also increased the proportion of dead CF and MF in a dose dependent manner. However, treatment with Rsv did not induce cell death in adult cardiomyocytes. There was an increase in the percentage of cells with condensed nuclei with Rsv treatment in both CF and MF, but not in cardiomyocytes. Treatment with estrogen, tamoxifen and fulvestrant alone or in combination with Rsv did not have any additional effects on CF survival. Our results demonstrate that treatment with Rsv can inhibit cell proliferation and induce cell death in rat CF and MF, while not affecting cardiomyocyte survival. We also demonstrated that the induction of cell death in CF with Rsv treatment was independent of estrogen receptor alpha $(E R \alpha)$ signaling.
\end{abstract}

Keywords: cardiac fibrosis; resveratrol; cardiac fibroblasts; cardiomyocytes

\section{Introduction}

Heart failure (HF) is the end stage clinical manifestation of heart disease [1]. HF is a growing epidemic in Canada, with 50,000 new cases diagnosed each year [2]. Cardiac fibroblasts and cardiomyocytes are two cell types that play major roles in normal cardiac function, as well as in HF [3-5]. During a myocardial infarction (MI), cardiomyocytes die due to a lack of blood supply [6]. After cardiomyocyte death and the subsequent inflammatory response to clear damaged cells and debris, resident cardiac fibroblasts (CF) are activated and initiate the wound healing process [7]. Activated resident CF convert 
into myofibroblasts (MF) that secrete elevated levels of extracellular matrix (ECM) proteins to maintain the structural integrity of the heart, which was compromised due to loss of cardiomyocytes from MI [8]. Prolonged activation of MF leads to excessive ECM secretion in the remaining healthy regions of the heart, causing stiffening of the myocardium and reduced heart function, which further progresses into heart failure [3].

Nutraceuticals, the component of food that provides health benefits, have been increasingly explored as supplementary therapies for heart disease $[9,10]$. Recently, the polyphenol, resveratrol (Rsv), has been investigated as a possible cardioprotective nutraceutical [11]. Rsv is found in the skin of grapes, blueberries, raspberries and mulberries [10]. We previously published a review that discussed studies reporting beneficial effects of Rsv in preventing and reversing abnormalities in cardiac function and structure [12]. Rsv is also a phytoestrogen, a class of compounds with a structure similar to that of estrogen (E2). It has been suggested that the cardioprotective properties of Rsv may be mediated through E2 signaling [13]. Moreover, it is intriguing that Rsv can induce cell death in some cell populations while preventing cell death in other cell types [14]. This cell type specific mechanism of action is potentially a beneficial property for a cardiovascular drug as it may prevent cardiomyocyte death while inducing cell death in proliferating CFs and MFs after cardiac injury. In this study, we compared the effects of Rsv in vitro on the survival of primary rat CFs, MFs, and cardiomyocytes. We also examined the effect of Rsv on MF and CF proliferation.

\section{Results}

\subsection{Comparing the Dose Dependent Effect of Resveratrol on Fibroblast, Myofibroblast and Cardiomyocyte Cell Death}

Cell count analyses of red and green stained cells representing live and dead cells, respectively, showed that Rsv treatment increased the percentage of dead cells in both CF and MF in a dose dependent manner (Figure 1A-C). The 30 and $60 \mu \mathrm{M}$ doses of Rsv significantly increased cell death in $\mathrm{CF}$ and MF. There was no difference in the percentage of dead cells between Rsv 30 and $60 \mu \mathrm{M}$ doses. The percentage of dead cells increased by $50 \%$ with Rsv treatment in both CF and MF. There was no difference in the percentage of dead cells between untreated MF and CF (Figure 1C). In cardiomyocytes, dead cardiomyocytes (red) were counted by considering cell morphology. Rsv treatment did not alter the rate of cardiomyocyte cell death (Figure 1C). Treated or untreated cardiomyocytes had a significantly lower percentage of dead cells as compared to CF and MF (Figure 1C). Among the cardiomyocytes, the small red dots (significantly smaller and morphologically different from dead cardiomyocytes) observed are likely cellular debris or fragments, which were counted separately; no differences were observed between control and Rsv treated groups (data not presented).

\subsection{Quantification of CF and MF Proliferation}

Analyses of cell proliferation using the Cytoquant assay showed that treatment with Rsv decreased total nucleic acid content in both $\mathrm{CF}$ and $\mathrm{MF}$, as demonstrated by decreased fluorescent intensity measurements with Rsv treatment in both cell types (Figure 2A). The decrease in intensity was $46 \%$ and $42 \%$ for CFs and MFs, respectively. Basal fluorescent intensity in untreated MF was lower than the untreated $\mathrm{CF}$, suggesting that the rate of proliferation may slow down as the fibroblasts phenoconvert into MF (Figure 2A).

To further study the effect of Rsv on cellular proliferation, a BrdU incorporation assay was performed. This experiment showed that incubation with Rsv significantly decreased MF proliferation, when compared to vehicle treated control cells (Figure 2B). There was a 58\% reduction in $\mathrm{MF}$ proliferation with Rsv treatment. 

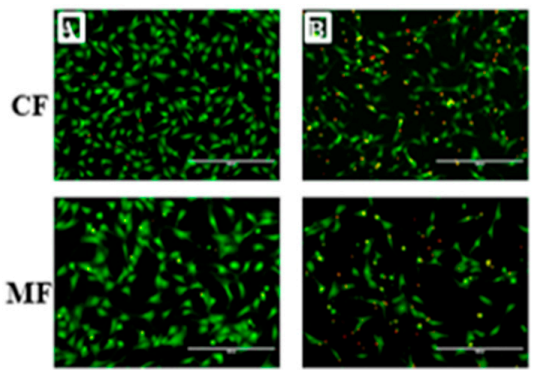

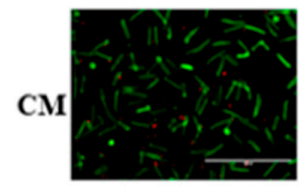

Ctrl

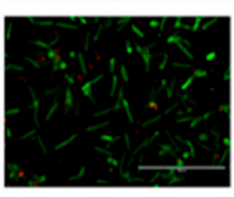

Rsv

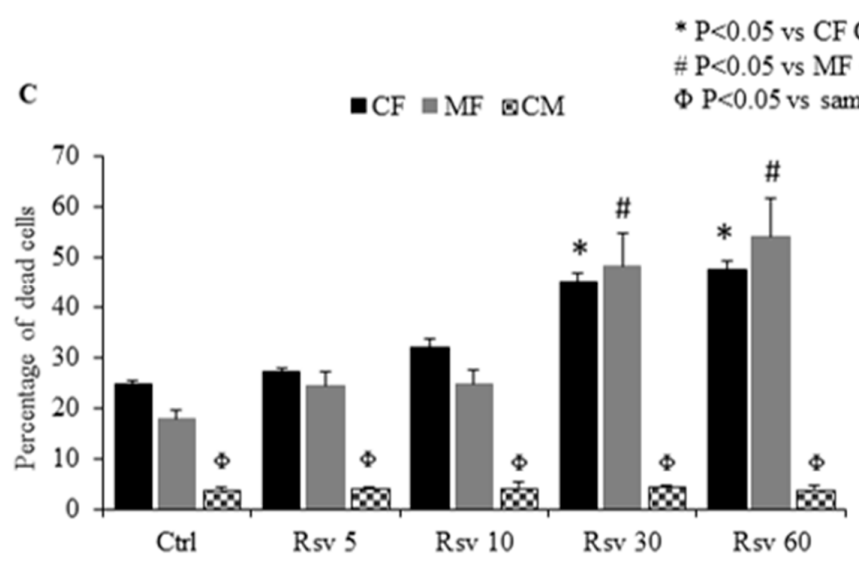

Figure 1. Dose dependent effect of resveratrol (Rsv) on cell survival of cardiac fibroblast (CF) myofibroblasts (MF) and cardiomyocytes (CM). Representative images of merged green and red fluorescence channels from calcein AM and ethidium homodimer 1 dyes are presented here. Cells appearing as yellow or red in the merged image are considered as dead cells. First row shows CF, second row shows MF and third row shows CM. Panel (A) represents control (Ctrl) and panel (B) represents Rsv $30 \mu \mathrm{M}$. (C) Graphical representation shows percentage of dead cells in CF, MF and CM in Ctrl and Rsv (5,10,30,60 $\mu \mathrm{M})$ groups. $N=4$. ${ }^{*} P<0.05$ vs. CF Ctrl; $\# P<0.05$ vs. MF Ctrl; $\Phi P<0.05$ vs. same treatment group $C F$ and MF.

\subsection{Effect of Rsv on Fibroblasts and Cardiomyocyte Apoptosis}

Hoechst staining showed that Rsv treatment significantly increased the proportion of CFs and MFs with condensed, apoptotic nuclei (Figure 3A,B). Rsv treatment increased the percentage of apoptotic cells with condensed nuclei by $72 \%$ and $62 \%$ in $\mathrm{CF}$ and MF, respectively (Figure 3D). In contrast, Rsv treatment did not increase the number of cardiomyocytes with condensed, apoptotic nuclei (Figure 3C,D).

\subsection{Effect of Estradiol, Tamoxifen and Fulvestrant on Cardiac Fibroblasts}

Treatment with E2 did not affect CF cell survival when compared to untreated controls (Figure 4A). Co-incubating CF with E2 and Rsv also did not have any added effect when compared to cells treated with Rsv alone (Figure 4B). Incubation with the estrogen receptor modulator Tmx or the estrogen receptor alpha $(\mathrm{ER} \alpha)$ specific antagonist fulvestrant alone did not induce any changes in CF survival, and the addition of Tmx or fulvestrant prior to Rsv treatment did not alter the rate of cell death as compared to that induced by Rsv alone (Figure 4B,C). 


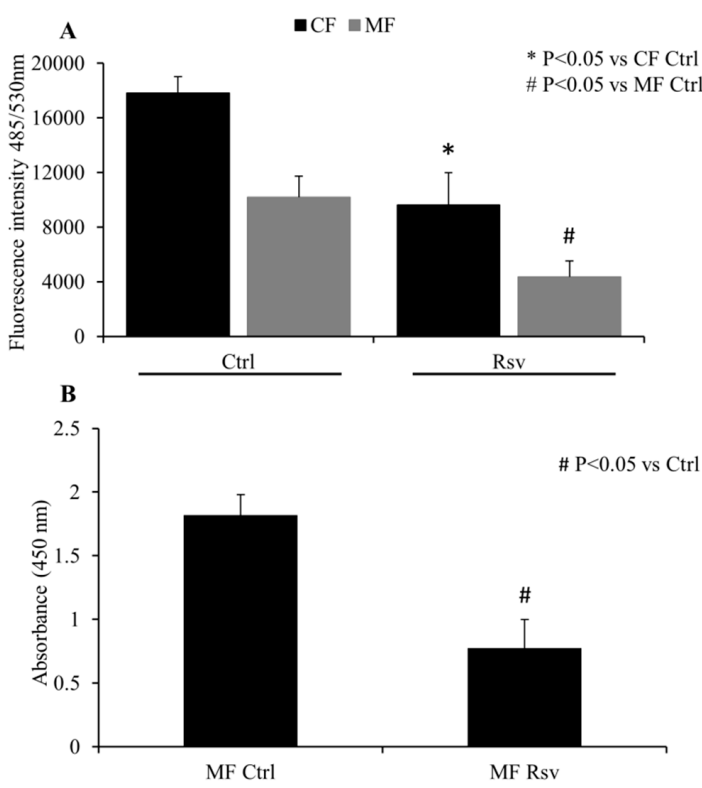

Figure 2. Effect of resveratrol (Rsv) on cardiac fibroblast (CF) and myofibroblast (MF) proliferation. (A) Relative cell count was measured as fluorescence intensity by spectrophotometer (excitation $485 \mathrm{~nm} / \mathrm{emission} 530 \mathrm{~nm}$ ) in CF and MF. $N=4$. (B) MF proliferation measured by BrdU cell proliferation assay. $\mathrm{N}=4 .{ }^{*} P<0.05$ vs. CF Ctrl; $\# P<0.05$ vs. MF Ctrl.

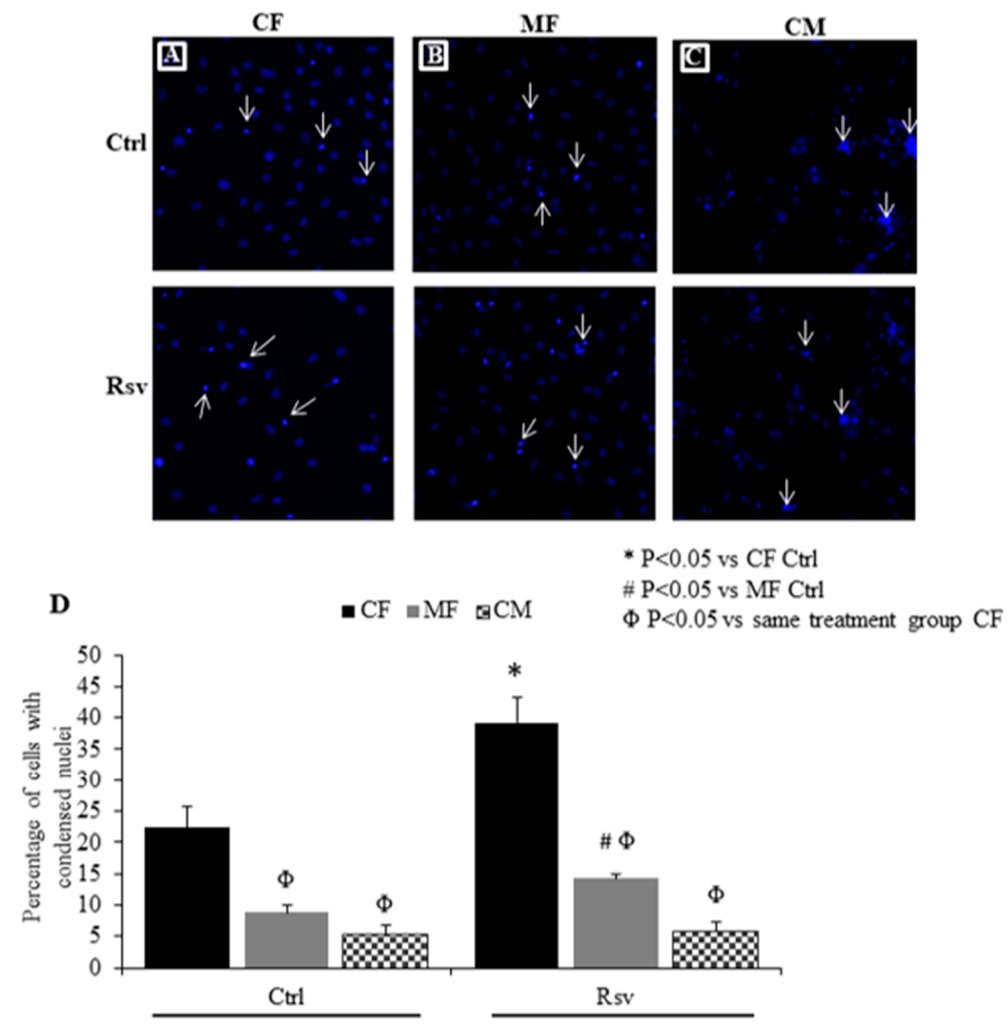

Figure 3. Effect of resveratrol (Rsv) in inducing apoptosis in cardiac fibroblast (CF) myofibroblasts (MF) and cardiomyocytes (CM). Representative images of CF, MF and CM with blue fluorescence from Hoechst dye. Arrows shows cells with condensed nuclei. Panel (A) represents control (Ctrl) and panel (B) represents Rsv $(30 \mu \mathrm{M})$ treated groups. First row represents $\mathrm{CF}$, second row represents $\mathrm{MF}$ and third row represents CM. (C,D) Graphical representation of percentage of $\mathrm{CF}, \mathrm{MF}$ and $\mathrm{CM}$ with condensed nuclei. $N=4$. ${ }^{*} P<0.05$ vs. CF Ctrl; $\# P<0.05$ vs. MF Ctrl; $\Phi P<0.05$ vs. same treatment group CF; $¥ P<0.05$ vs. same treatment group MF. 
A

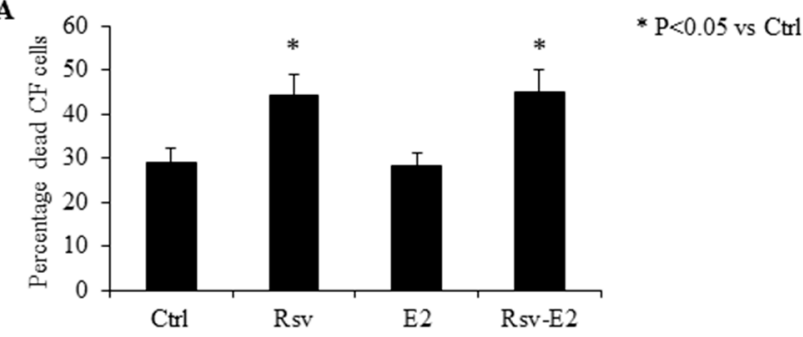

B

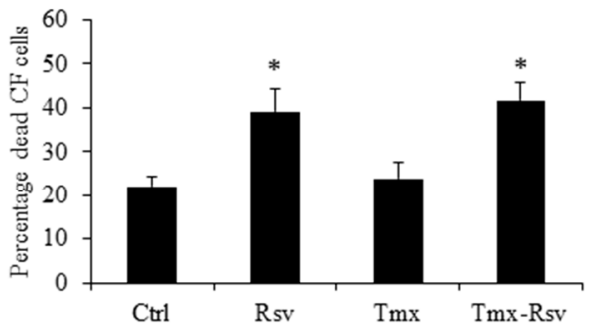

C

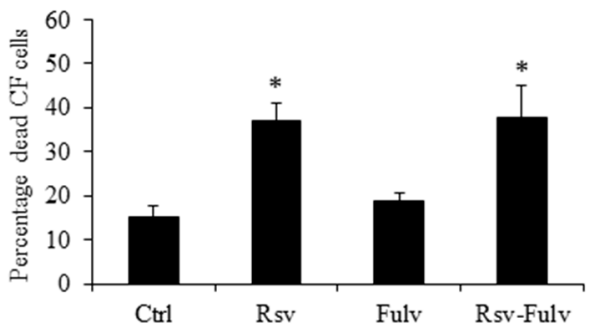

Figure 4. Resveratrol mediated cell death in cardiac fibroblasts (CF) is independent of estrogen receptor alpha signaling. Effect of (A) estrogen (E2), (B) tamoxifen (Tmx) and (C) fulvestrant (Fulv) on cell survival of cardiac fibroblasts (CF) treated with and without resveratrol (Rsv). Total percentages of dead cells were calculated from live and dead assay. $N=4-6$. Control, $\mathrm{Ctrl} .{ }^{*} P<0.05$ vs. ctrl.

\section{Discussion}

The proliferation of CF and their conversion into MF in response to pressure overload or ischemia reperfusion injury is a key pathological step in cardiac fibrosis and a contributor to development of HF [3,6]. There is no effective therapy against cardiac fibrosis, and this has been a hurdle in developing cardiovascular drugs that inhibit the progression of heart diseases into HF [15]. Blocking the angiotensin II signaling that stimulates MF activation was considered a potential therapeutic target [16]. However, anti-fibrotic drugs belonging to the class of angiotensin receptor blockers were hindered by the development of adverse side effects [17]. These challenges highlight the importance of natural polyphenolic molecules like Rsv with potential cardioprotective properties. Rsv has been demonstrated to be well tolerated by older and sicker populations, who are more at risk to any possible side effects of drugs and also more at risk of developing HF [18-20]. To date, Rsv treatment has been shown to have minimal side effects often only observed at very high concentrations, which makes it an ideal candidate to test for anti-fibrotic properties [21]. In this study, we found that Rsv induced cell death in both CF and MF in a dose dependent manner. Rsv also increased the rate of apoptotic cell death in both CF and MF. However, Rsv did not induce adult cardiomyocyte cell death or apoptosis at any doses tested in this study. We also demonstrated that Rsv reduced CF and MF cellular proliferation. In this study, addition of estrogen or inhibition of estrogen signaling by Tmx (Selective ER modulator) or Fulvestrant (ER $\alpha$ specific antagonist) receptor had no effect on the action of Rsv on fibroblasts.

We have previously reported that Rsv protects adult rat cardiomyocytes from oxidative stress and norepinephrine induced damages in vitro [22,23] and protects the heart in vivo [13,24-27]. In the in vivo studies, we showed an improvement in systolic and diastolic function of the heart, which suggests that Rsv treatment may have helped maintain cardiac tissue elasticity, possibly through restricting 
cardiac fibrosis [8]. Ameliorating the pathophysiological process of fibrosis and subsequent decrease in collagen deposition was reported to be associated with Rsv mediated cardioprotection [28]. The data from this study using adult rat cardiac fibroblasts confirms these in vivo findings by showing that Rsv inhibits the proliferation of both CF and MF. In this study we showed that Rsv treatment increased the rate of cell death in both CF and MF. The resident cardiac fibroblast population has a role in the normal physiological function and removing those cells could affect normal function of the heart. In this study, we observed that Rsv induce cell death in CF. However, these cells are actively proliferating and becoming activated in culture. Moreover, it has been shown that Rsv reduces fibrosis in the pathological heart, but normal rat heart functions were unaffected in control animals [24]. This suggests that Rsv may preferentially target the MF population in vivo. Another concern would be if Rsv induces cell death in other cardiac cell types. In this study, we observed that when treated with the same doses of Rsv, cardiomyocyte cell survival was unaffected. This observation is consistent with our previous report that Rsv protected neonatal cardiomyocytes against norepinephrine induced apoptosis, while inducing apoptosis in proliferating cardiac tumor cells [14]. Rsv induces cell cycle arrest, down regulates cellular survival mechanisms, disrupts mitochondrial function and induces apoptotic signaling to trigger cell death in highly proliferative, transformed cancer cells [29]. In contrast, Rsv promotes cell survival through a different mechanism involving decreasing oxidative stress, inflammation, improving mitochondrial function and activating anti-apoptotic mechanisms [30,31]. This is a therapeutically relevant property of Rsv that, at the same concentration, Rsv can alter cell survival differently according to specific cell type being studied. We observed an increase in the percentage of cells with condensed nuclei (a hallmark of apoptosis) in CF and MF but not in cardiomyocytes. This suggests that Rsv induces cell death in CF and MF through apoptosis. Rsv treatment reduced cellular proliferation of both CF and MF. Therefore, our data suggest that Rsv may limit the pathological effects of cardiac fibrosis by limiting CF/MF expansion through a combination of decreasing proliferation and inducing cell death.

Rsv has been shown to function via ER $\alpha$ in neural and vascular smooth muscle cells [32,33] and Rsv attenuates cardiac dysfunction due to E2 deficiency [34]. Similar to E2, Rsv activates downstream targets like 5' AMP-activated protein kinase (AMPK), endothelial nitric oxide synthase (eNOS), NAD-dependent deacetylase sirtuin-1 (SIRT1) and antioxidant enzymes, suggesting that they share a common signaling pathway [35]. There is strong evidence suggesting that the phytoestrogenic property of Rsv is a major contributor to its cardioprotective effects [13]. Several studies have shown that Rsv mediated cardiovascular protection is mediated through upregulating ER $\alpha$ or by activating downstream proteins in ER $\alpha$ signaling pathway [36-38]. Comparatively, in this study, activation of ER $\alpha$ using E2 alone did not alter CF death. There was also no synergistic effect when E2 was co-incubated with Rsv, suggesting a role for a non-ER mediated signaling in CF death induced by Rsv. This was further supported by using Tmx that blocks both ER $\alpha$ and ER $\beta$ prior to Rsv addition. We also used Fulvestrant, which is a selective estrogen receptor degrader that has higher affinity to ER $\alpha$ receptor. Pre-incubation with Tmx or fulvestrant had no effect on Rsv mediated CF death suggesting an ER independent signaling with Rsv. Our finding is consistent with an earlier study using CFs and showed that Rsv treatment did not affect protein kinase B and ribosomal protein S6 kinase beta-1 (Akt/p70S6K) activity, which are downstream targets of ER signaling [39]. The same study showed that Rsv inhibited CF proliferation induced by angiotensin II through inhibition of mitogen-activated protein kinase (MAPK) signaling. Accordingly, we suggest that Rsv may be acting on CF by inhibiting growth signaling, rather than inducing cell death through the classical ER pathway.

In conclusion, this study shows that in adult rat CF and MF, Rsv reduces proliferation and induces cell death, while adult rat cardiomyocyte viability was unaffected by Rsv treatment. Rsv mediated CF death was independent of ER-alpha signaling. Further studies are required to elucidate the exact mechanism of action of Rsv on CF. This study reinforces the potential of Rsv as a cardioprotective agent that could possibly be used in the future as a supplementary therapy against cardiac diseases involving cardiac fibrosis. 


\section{Materials and Methods}

The experimental protocol used in this project were approved (protocol number 17-003) by the University of Manitoba Office of Research Ethics and Compliance and Animal Care Committee and were conducted in accordance with guidelines by the Canadian Council for Animal Care.

\subsection{Adult Cardiomyocyte and Fibroblast Isolation and Culture}

All chemicals used for primary cell isolation were purchased from Sigma-Aldrich (Oakville, ON, Canada). Adult cardiomyocytes and fibroblasts were isolated from 10-week old male Sprague-Dawley rats weighing around 250-300 g from the University of Manitoba animal breeding facility. Briefly, rats were anesthetized using ketamine/xylazine $(90 / 10 \mathrm{mg} / \mathrm{kg}$ body weight) administration. Heparin (1000 USP units/kg body weight) was administered intravenously through the left femoral artery. The heart was then excised and transferred to ice cold saline solution. The heart was rinsed with saline solution and mounted on the Langendorff perfusion apparatus. The heart was perfused with calcium-free buffer containing (in mmol/L) $\mathrm{NaCl} 90, \mathrm{KCl} 10, \mathrm{KH}_{2} \mathrm{PO}_{4} 1.2, \mathrm{MgSO}_{4} \cdot 7 \mathrm{H}_{2} \mathrm{O} 5.0$, $\mathrm{NaHCO}_{3} 15$, taurine 30, glucose 20, pH 7.4 and collagenase $(0.5 \mathrm{mg} / \mathrm{mL})$ for $40 \mathrm{~min}$. The ventricles were dissected into 8-10 pieces and incubated in $10 \mathrm{~mL} \mathrm{Ca}^{2+}$ free buffer collected from the Langendorff system, in $37^{\circ} \mathrm{C}$ water bath for $10 \mathrm{~min}$. Cells were separated from the tissue by repeated pipetting using a $5 \mathrm{~mL}$ pipette. The supernatant was transferred into a fresh $50 \mathrm{~mL}$ tube. The cells collected in the $50 \mathrm{~mL}$ tube were left undisturbed for $5 \mathrm{~min}$ and then the supernatant containing fibroblasts were transferred into a separate $50 \mathrm{~mL}$ tube. This step was repeated 4-5 times. The sedimented cells were used for cardiomyocyte experiments as described earlier [22]. A penicillin/streptomycin (Gibco, Life Technologies, ON, Canada) antibiotic mixture was added to tube containing fibroblasts and was centrifuged at $2000 \mathrm{rpm}$ for $5 \mathrm{~min}$ in room temperature. The pellet was re-suspended in sterile phosphate buffer saline (PBS) with penicillin/streptomycin antibiotic mixture and centrifuged again at $2000 \mathrm{rpm}$ for $5 \mathrm{~min}$ in room temperature. The pellet was re-suspended in DMEM-F12 medium (ThermoFisher Scientific, Ottawa, ON, Canada) with 10\% fetal bovine serum (FBS; SigmaAldrich, Oakville, ON, Canada) and penicillin/streptomycin antibiotic mixture, plated $2 \mathrm{~mL} /$ well into 6 well plates and incubated at $37^{\circ} \mathrm{C}$ in a $\mathrm{CO}_{2}$ incubator. The cardiomyocytes were plated onto 6 well plates after transferring through increasing concentrations of $\mathrm{Ca}^{2+}$ and finally suspending in M199 medium (ThermoFisher Scientific, Ottawa, ON, Canada) with 10\% FBS. After 2-3 h, CF were washed two times with sterile PBS and incubated in fresh DMEM-F12 medium supplemented with 10\% FBS until the day of experimentation. For cardiomyocytes, the medium was replaced with fresh serum free M199 medium supplemented with $5 \mathrm{mM}$ taurine, $2 \mathrm{mM}$ carnitine, $1 \mathrm{mM}$ creatine and $1 \mu \mathrm{mol}$ insulin, and incubated until experimentation. After $48 \mathrm{~h}, \mathrm{CF}$ were either treated as outlined below or treated with trypsin and seeded onto new plates at 1:2 ratio and maintained in DMEM-F12 medium with 10\% FBS overnight. These cells were considered as myofibroblasts (MF) after $72 \mathrm{~h}$ of culture post-isolation (or $24 \mathrm{~h}$ after re-seeding) [40,41].

\subsection{Dose Dependent Effect of Resveratrol on Cardiac Fibroblasts, Myofibroblasts and Cardiomyocytes}

Rsv was dissolved in 100\% dimethyl sulfoxide (DMSO) and then diluted with sterile water to prepare a $50 \%$ DMSO solution at $60 \mathrm{mM}$ stock concentration. CF or MF medium with $10 \%$ serum was replaced with serum free media $3 \mathrm{~h}$ before the Rsv treatment. Cells were maintained in serum free medium until the end of the experiment. CF, MF and cardiomyocytes were treated for $24 \mathrm{~h}$ with a range of Rsv doses $(5,10,30$ and $60 \mu \mathrm{M})$ or vehicle control. Live dead cell assay was used to determine the effect of resveratrol on CF, MF and cardiomyocytes. Briefly, $24 \mathrm{~h}$ after treatment with Rsv, CM, MF and cardiomyocytes were incubated with calcein AM (Invitrogen, ON, Canada) and ethidium homodimer 1 (Biotium, CA, USA) for $20 \mathrm{~min}$. Ethidium homodimer 1 is highly positively charged and hence non-permeable in live cells. It enters cells with damaged membrane and emits red fluorescence when bound to DNA. Calcein AM is a cell permeable dye that gets converted to its fluorescent form after 
hydrolysis by intracellular esterases and is used to detect viable cells. Red and green cells were imaged using EVOSfl fluorescent microscope (AMG, ThermoFisher Scientific, MA, USA) at a 10× magnification. The images were analyzed using ImageJ software. All analyses were done in a blinded manner.

\subsection{Quantification of CF and MF Proliferation}

To examine effect of Rsv on CF and MF cell growth, we used a CyQUANT Direct Cell Proliferation Assay kit (Invitrogen, Ottawa, ON, Canada) according to manufacturer's protocol. CF and MF were incubated with CyQUANT nucleic acid stain and background suppressor solution for 30 min at the end of the $24 \mathrm{~h}$ treatment. For CF, the cell count was not determined before seeding because the initial population of cells are heterogeneous. Comparable numbers of cells were plated in each well by thoroughly mixing the cell solution before seeding. Seeding density was visually confirmed before treating the cells with Rsv. In contrast to other cell types, fibroblasts are not washed off during medium change ( $24 \mathrm{~h}$ post isolation) and proliferate rapidly resulting in a homogenous population at $48 \mathrm{~h}$. Fluorescence intensity of nucleic acid staining was read at 485/530 nm (excitation/emission) using a Cytation 5 imaging reader (BioTek, VT, USA). An increase or decrease in fluorescence intensity is directly proportional to the DNA content which in turn is directly proportional to the total number of live cells.

To measure the effect of Rsv on MF proliferation, fibroblasts were trypsinized $48 \mathrm{~h}$ after isolation and reseeded at a density of $1 \times 10^{5}$ cells per well in a 96 well plate in DMEM-F12 medium with $10 \%$ serum; after $24 \mathrm{~h}$ bromodeoxyuridine 5-bromo-2'-deoxyuridine (BrdU) cell proliferation assay kit (Millipore (Canada) Ltd., Etobicoke, ON, Canada) was used to measure MF proliferation. BrdU label was added with Rsv $(30 \mu \mathrm{M})$ in DMEM-F12 medium without serum and incubated with the cells for further $24 \mathrm{~h}$. At $96 \mathrm{~h}$ after isolation, cells (MF) were fixed and processed according to the manufacturer's protocol (Millipore (Canada) Ltd., Etobicoke, ON, Canada). Two negative controls were used for this assay, (1) without cells but with BrdU label; and (2) with cells, but no BrdU label.

\subsection{Measurement of Apoptotic Cells}

Hoechst assay was used to detect apoptotic cells in CF, MF and cardiomyocytes. Twenty-four hours after Rsv treatment, CF, MF and cardiomyocytes were incubated with $1.5 \mu \mathrm{L} /$ well Hoechst 3342 dye (10 mg/mL; ThermoFisher, Ottawa, ON, Canada) for $20 \mathrm{~min}$ in $\mathrm{CO}_{2}$ incubator. Cells were then imaged using EVOSfl fluorescent microscope at 10X magnification. The images were analyzed using ImageJ software.

\subsection{Fibroblast Treatment with Estrogen, Tamoxifen and Fulvestrant}

Estrogen, tamoxifen (Tmx) and fulvestrant were dissolved in 100\% DMSO at a concentration of 1 $\mathrm{mM}$. Forty-eight hours after isolation, in separate experiments, CF were either treated with $1 \mu \mathrm{M} \mathrm{E2,}$ (Cayman Chemical, MI, USA) or $250 \mu \mathrm{M}$ Tmx (Cayman Chemical, MI, USA) or $100 \mathrm{nM}$ fulvestrant (Sigma Aldrich, ON, Canada) for 30 min before incubating with Rsv for $24 \mathrm{~h}$. The live and dead assay was performed after the $24 \mathrm{~h}$ of treatment as described earlier.

\subsection{Statistics}

Prism Graphpad software (version 5.0) was used for all statistical analyses used in this study. Two-Way-ANOVA was used to analyze dose dependent cell death data. Two tailed student t-test was used to analyze BrdU cell proliferation assay data. All other data were analyzed by one-way ANOVA with Tukey post-hoc test. P value less than 0.05 was considered significant.

Author Contributions: Conceptualization, X.L.L., T.N. and J.T.W.; methodology, X.L.L., T.N. and J.T.W.; formal analysis, X.L.L., T.N. and J.T.W.; investigation, X.L.L., Z.M., L.C., G.D., R.C., S.M., S.K. and L.Y.; validation, X.L.L.; resources, T.N. and J.T.W.; data curation, X.L.L.; writing-original draft preparation, X.L.L.; writing-review and editing, X.L.L., Z.M.; L.C., R.C., T.N. and J.T.W.; visualization, X.L.L.; supervision, X.L.L., T.N. and J.T.W.; project administration, T.N. and J.T.W.; funding acquisition, T.N. and J.T.W. 
Funding: This research was funded by a St. Boniface Hospital Foundation's Research Without Borders grant. L.C. and S.M. were supported by studentships from the Institute of Cardiovascular Sciences and the Department of Cardiology, University of Manitoba.

Acknowledgments: We acknowledge St. Boniface Hospital Foundation and the St. Boniface Hospital Albrechtsen Research Centre for their ongoing support of our research programs.

Conflicts of Interest: The authors declare no conflict of interest.

\section{References}

1. Tanai, E.; Frantz, S. Pathophysiology of Heart Failure. Compr. Physiol. 2015, 6, 187-214. [CrossRef] [PubMed]

2. Foundation, H.A.S. The Burden of Heart Failure. In 2016 Report on the health of Canadians; 2016; Available online: https://www.heartandstroke.ca/-/media/pdffiles/canada/2017-heart-month/heartandstroke-reportonhealth-2016.ashx?la=en\&hash= 91708486C91708481BC91708014E91708424AB91708484E91708719B91708447AEEB91708488C91708485EB91708493E (accessed on 15 July 2019).

3. Dostal, D.; Glaser, S.; Baudino, T.A. Cardiac fibroblast physiology and pathology. Compr. Physiol. 2015, 5, 887-909. [CrossRef] [PubMed]

4. Ivey, M.J.; Tallquist, M.D. Defining the Cardiac Fibroblast. Circ. J. Off. J. Jpn. Circ. Soc. 2016, 80, $2269-2276$. [CrossRef] [PubMed]

5. Severs, N.J. The cardiac muscle cell. Bioessays: News Rev. Mol. Cell. Dev. Biol. 2000, 22, 188-199. [CrossRef]

6. Marin-Garcia, J. Cell death in the pathogenesis and progression of heart failure. Heart Fail. Rev. 2016, 21, 117-121. [CrossRef]

7. Briasoulis, A.; Androulakis, E.; Christophides, T.; Tousoulis, D. The role of inflammation and cell death in the pathogenesis, progression and treatment of heart failure. Heart Fail. Rev. 2016, 21, 169-176. [CrossRef] [PubMed]

8. Travers, J.G.; Kamal, F.A.; Robbins, J.; Yutzey, K.E.; Blaxall, B.C. Cardiac Fibrosis: The Fibroblast Awakens. Circ. Res. 2016, 118, 1021-1040. [CrossRef]

9. Cicero, A.F.G.; Colletti, A. Nutraceuticals and Dietary Supplements to Improve Quality of Life and Outcomes in Heart Failure Patients. Curr. Pharm. Des. 2017, 23, 1265-1272. [CrossRef]

10. Johnston, T.P.; Korolenko, T.A.; Pirro, M.; Sahebkar, A. Preventing cardiovascular heart disease: Promising nutraceutical and non-nutraceutical treatments for cholesterol management. Pharmacol. Res. 2017, 120, 219-225. [CrossRef]

11. Dyck, G.J.B.; Raj, P.; Zieroth, S.; Dyck, J.R.B.; Ezekowitz, J.A. The Effects of Resveratrol in Patients with Cardiovascular Disease and Heart Failure: A Narrative Review. Int. J. Mol. Sci. 2019, 20, 904. [CrossRef]

12. Raj, P.; Zieroth, S.; Netticadan, T. An overview of the efficacy of resveratrol in the management of ischemic heart disease. Ann. New York Acad. Sci. 2015, 1348, 55-67. [CrossRef] [PubMed]

13. Lieben Louis, X.; Raj, P.; Chan, L.; Zieroth, S.; Netticadan, T.; Wigle, J.T. Are the cardioprotective effects of the phytoestrogen resveratrol sex dependent? Can. J. Physiol. Pharmacol. 2018, 10. [CrossRef]

14. Baarine, M.; Thandapilly, S.J.; Louis, X.L.; Mazue, F.; Yu, L.; Delmas, D.; Netticadan, T.; Lizard, G.; Latruffe, N. Pro-apoptotic versus anti-apoptotic properties of dietary resveratrol on tumoral and normal cardiac cells. Genes Nutr. 2011, 6, 161-169. [CrossRef] [PubMed]

15. Fang, L.; Murphy, A.J.; Dart, A.M. A Clinical Perspective of Anti-Fibrotic Therapies for Cardiovascular Disease. Front. Pharmacol. 2017, 8, 186. [CrossRef] [PubMed]

16. Talman, V.; Ruskoaho, H. Cardiac fibrosis in myocardial infarction-from repair and remodeling to regeneration. Cell Tissue Res. 2016, 365, 563-581. [CrossRef] [PubMed]

17. Serpi, R.; Tolonen, A.M.; Tenhunen, O.; Pievilainen, O.; Kubin, A.M.; Vaskivuo, T.; Soini, Y.; Kerkela, R.; Leskinen, H.; Ruskoaho, H. Divergent effects of losartan and metoprolol on cardiac remodeling, c-kit+ cells, proliferation and apoptosis in the left ventricle after myocardial infarction. Clin. Transl. Sci. 2009, 2, 422-430. [CrossRef] [PubMed]

18. Anton, S.D.; Embry, C.; Marsiske, M.; Lu, X.; Doss, H.; Leeuwenburgh, C.; Manini, T.M. Safety and metabolic outcomes of resveratrol supplementation in older adults: Results of a twelve-week, placebo-controlled pilot study. Exp. Gerontol. 2014, 57, 181-187. [CrossRef] [PubMed] 
19. Fodor, K.; Tit, D.M.; Pasca, B.; Bustea, C.; Uivarosan, D.; Endres, L.; Iovan, C.; Abdel-Daim, M.M.; Bungau, S. Long-Term Resveratrol Supplementation as a Secondary Prophylaxis for Stroke. Oxidative Med. Cell. Longev. 2018, 2018, 4147320. [CrossRef]

20. Dunlay, S.M.; Roger, V.L.; Redfield, M.M. Epidemiology of heart failure with preserved ejection fraction. Nature reviews. Cardiology 2017, 14, 591-602. [CrossRef]

21. Novelle, M.G.; Wahl, D.; Dieguez, C.; Bernier, M.; de Cabo, R. Resveratrol supplementation: Where are we now and where should we go? Ageing Res. Rev. 2015, 21, 1-15. [CrossRef]

22. Thandapilly, S.J.; Louis, X.L.; Yang, T.; Stringer, D.M.; Yu, L.; Zhang, S.; Wigle, J.; Kardami, E.; Zahradka, P.; Taylor, C.; et al. Resveratrol prevents norepinephrine induced hypertrophy in adult rat cardiomyocytes, by activating NO-AMPK pathway. Eur. J. Pharmacol. 2011, 668, 217-224. [CrossRef] [PubMed]

23. Movahed, A.; Yu, L.; Thandapilly, S.J.; Louis, X.L.; Netticadan, T. Resveratrol protects adult cardiomyocytes against oxidative stress mediated cell injury. Arch. Biochem. Biophys. 2012, 527, 74-80. [CrossRef] [PubMed]

24. Thandapilly, S.J.; Louis, X.L.; Behbahani, J.; Movahed, A.; Yu, L.; Fandrich, R.; Zhang, S.; Kardami, E.; Anderson, H.D.; Netticadan, T. Reduced hemodynamic load aids low-dose resveratrol in reversing cardiovascular defects in hypertensive rats. Hypertens. Res. Off. J. Jpn. Soc. Hypertens. 2013, 36, 866-872. [CrossRef] [PubMed]

25. Wojciechowski, P.; Juric, D.; Louis, X.L.; Thandapilly, S.J.; Yu, L.; Taylor, C.; Netticadan, T. Resveratrol arrests and regresses the development of pressure overload- but not volume overload-induced cardiac hypertrophy in rats. J. Nutr. 2010, 140, 962-968. [CrossRef] [PubMed]

26. Juric, D.; Wojciechowski, P.; Das, D.K.; Netticadan, T. Prevention of concentric hypertrophy and diastolic impairment in aortic-banded rats treated with resveratrol. Am. J. Physiology. Heart Circ. Physiol. 2007, 292, H2138-H2143. [CrossRef]

27. Raj, P.; Aloud, B.M.; Louis, X.L.; Yu, L.; Zieroth, S.; Netticadan, T. Resveratrol is equipotent to perindopril in attenuating post-infarct cardiac remodeling and contractile dysfunction in rats. J. Nutr. Biochem. 2016, 28, 155-163. [CrossRef] [PubMed]

28. Chen, T.; Li, J.; Liu, J.; Li, N.; Wang, S.; Liu, H.; Zeng, M.; Zhang, Y.; Bu, P. Activation of SIRT3 by resveratrol ameliorates cardiac fibrosis and improves cardiac function via the TGF-beta/Smad3 pathway. Am. J. Physiology. Heart Circ. Physiol. 2015, 308, H424-H434. [CrossRef]

29. Fulda, S.; Debatin, K.M. Resveratrol modulation of signal transduction in apoptosis and cell survival: A mini-review. Cancer Detect. Prev. 2006, 30, 217-223. [CrossRef]

30. Price, N.L.; Gomes, A.P.; Ling, A.J.; Duarte, F.V.; Martin-Montalvo, A.; North, B.J.; Agarwal, B.; Ye, L.; Ramadori, G.; Teodoro, J.S.; et al. SIRT1 is required for AMPK activation and the beneficial effects of resveratrol on mitochondrial function. Cell Metab. 2012, 15, 675-690. [CrossRef]

31. Zhang, L.; Guo, X.; Xie, W.; Li, Y.; Ma, M.; Yuan, T.; Luo, B. Resveratrol exerts an anti-apoptotic effect on human bronchial epithelial cells undergoing cigarette smoke exposure. Mol. Med. Rep. 2015, 11, 1752-1758. [CrossRef]

32. Di Liberto, V.; Makela, J.; Korhonen, L.; Olivieri, M.; Tselykh, T.; Malkia, A.; Do Thi, H.; Belluardo, N.; Lindholm, D.; Mudo, G. Involvement of estrogen receptors in the resveratrol-mediated increase in dopamine transporter in human dopaminergic neurons and in striatum of female mice. Neuropharmacology 2012, 62, 1011-1018. [CrossRef] [PubMed]

33. Dubey, R.K.; Jackson, E.K.; Gillespie, D.G.; Zacharia, L.C.; Imthurn, B.; Rosselli, M. Resveratrol, a red wine constituent, blocks the antimitogenic effects of estradiol on human female coronary artery smooth muscle cells. J. Clin. Endocrinol Metab 2010, 95, E9-E17. [CrossRef] [PubMed]

34. Meng, Z.; Jing, H.; Gan, L.; Li, H.; Luo, B. Resveratrol attenuated estrogen-deficient-induced cardiac dysfunction: Role of AMPK, SIRT1, and mitochondrial function. Am. J. Transl. Res. 2016, 8, 2641-2649. [PubMed]

35. Zordoky, B.N.; Robertson, I.M.; Dyck, J.R. Preclinical and clinical evidence for the role of resveratrol in the treatment of cardiovascular diseases. Biochim. Et Biophys. Acta 2015, 1852, 1155-1177. [CrossRef] [PubMed]

36. Lu, Y.; Lu, X.; Wang, L.; Yang, W. Resveratrol attenuates high fat diet-induced mouse cardiomyopathy through upregulation of estrogen related receptor-alpha. Eur. J. Pharmacol. 2019, 843, 88-95. [CrossRef] [PubMed] 
37. Yurdagul, A., Jr.; Kleinedler, J.J.; McInnis, M.C.; Khandelwal, A.R.; Spence, A.L.; Orr, A.W.; Dugas, T.R. Resveratrol promotes endothelial cell wound healing under laminar shear stress through an estrogen receptor-alpha-dependent pathway. Am. J. Physiology. Heart Circ. Physiol. 2014, 306, H797-H806. [CrossRef]

38. Khandelwal, A.R.; Hebert, V.Y.; Dugas, T.R. Essential role of ER-alpha-dependent NO production in resveratrol-mediated inhibition of restenosis. Am. J. Physiology. Heart Circ. Physiol. 2010, 299, H1451-H1458. [CrossRef]

39. Olson, E.R.; Naugle, J.E.; Zhang, X.; Bomser, J.A.; Meszaros, J.G. Inhibition of cardiac fibroblast proliferation and myofibroblast differentiation by resveratrol. Am. J. Physiology. Heart Circ. Physiol. 2005, 288, H1131-H1138. [CrossRef]

40. Jahan, F.; Landry, N.M.; Rattan, S.G.; Dixon, I.M.C.; Wigle, J.T. The Functional Role of Zinc Finger E Box-Binding Homeobox 2 (Zeb2) in Promoting Cardiac Fibroblast Activation. Int. J. Mol. Sci. 2018, 19, 3207. [CrossRef]

41. Santiago, J.J.; Dangerfield, A.L.; Rattan, S.G.; Bathe, K.L.; Cunnington, R.H.; Raizman, J.E.; Bedosky, K.M.; Freed, D.H.; Kardami, E.; Dixon, I.M. Cardiac fibroblast to myofibroblast differentiation in vivo and in vitro: Expression of focal adhesion components in neonatal and adult rat ventricular myofibroblasts. Dev. Dyn. Off. Publ. Am. Assoc. Anat. 2010, 239, 1573-1584. [CrossRef]

Sample Availability: Samples of the compound Resv is available from the authors. 